\title{
PHASE BEHAVIOUR OF FIRST - ORDER SYSTEMS
}

\author{
Kaloyan Yankov \\ Faculty of Technics and Technologies, Trakia University, Bulgaria \\ Graf Ignatiev 38, 8600 Yambol, Bulgaria \\ e-mail: kaloyan.yankov@trakia-uni.bg
}

\begin{abstract}
The phase-plane method gives possibility to study the stability of systems described by linear and nonlinear differential equations. The article is devoted to the capabilities of MathCad for analysis of first order differential equations. An algorithm is proposed and Mathcad's specific operators for the construction and analysis of phase trajectories are described. Approaches for calculation of equilibrium points and determination the type of bifurcation in function of parameter are described. The proposed algorithm is applied to the dose-response curve of the antibiotic tubazid.
\end{abstract}

Keywords: phase portrait, phase trajectory, equilibrium point, stability analysis, bifurcation, Mathcad.

"That which is static and repetitive is boring. That which is dynamic and random is confusing. In between lies art." John A. Locke (1632-1704), British philosopher and medical researcher

\section{INTRODUCTION}

The stability of systems is investigated by analysis of their models, described with ordinary differential equations (ODE). But it is not always possible or appropriate for these equations to be solved. The availability of powerful tools for both numerical calculus and graphical presentation of results stimulates the use of indirect methods, in which obtaining a closed form solution is not a priority. The Phase Plane Method (PPM) is one of them. It builds the possible trajectories (phase) corresponding to different initial conditions. The independent parameter is excluded from the equations and the dependence of the process velocity on its quantitative changes is examined.

The Phase Plane method has several useful properties.

- As a graphical method, it presents the behaviour of the system for differently selected initial conditions, without solving the equations.

- PPM is very useful for qualitative assessment of the asymptotic behaviour of ODE models of I and II order - both linear and non-linear, for which their solution is a problem $[3,5]$.

- It is also applicable to higher order equations, but it has to be taken into account that its usage is complicated and the visibility of the results deteriorates [4]. This inconvenience is overcome if the high order system can be approximated by an ordinary differential equation from the second order, then applying PPM.

- A valuable tool is a bifurcation analysis that explores graphically the change in stability in function of a given parameter.

The aim of the present paper is to propose an algorithm for the study of systems described by first-order differential equations in the Phase Plane method with the tools of MathCad. Qualities that determine its use are simple and effective solving of mathematical problems both numerical and symbolic; an extremely good graphical user interface (GUI), combining text, formulas, graphics, programs; the presence of its own programming language, complementing the GUI. 


\section{IRTIIIE \\ Ipplied Researrches in Technics, Technologies ind Bductition \\ Journal of the Faculty of Technics and Technologies, Trakia University https:///ites.google.com/a/trakia-uni.bg/artte/}

\section{KEY FEATURES OF PHASE PLANE METHOD}

The phase plane method introduces a number of terms and concepts, depending on the specificity of its application. The main object of study is usually an autonomous differential equation of the first order:

$$
\begin{aligned}
& \frac{d y}{d x}=f(y) \\
& f(y) \text { is a function where the independent variable does not } \\
& \quad \text { appear explicitly; } \\
& \mathrm{y}\left(\mathrm{x}_{0}\right)=\mathrm{y}_{0} \text { - initial condition. }
\end{aligned}
$$

1. Phase plane. Eq.(1) determines the plane in which the graphs $f(y)$ are constructed under different initial conditions. The abscissa axis is the variable $\boldsymbol{y}$, and the ordinate axis $-\boldsymbol{d y} / \boldsymbol{d} \boldsymbol{x}$.

2. Phase trajectory. This is the graph of Eq.(1) through a selected initial point $\boldsymbol{y}_{0}$. Phase trajectories can be built for a wide range of initial conditions. Autonomy determines the receipt of trajectories that do not intersect. Tracking their behaviour allows a qualitative assessment of system dynamics. The set of all trajectories determines the system's phase portrait.

3. Equilibrium (fixed) points $\boldsymbol{y}^{\star}$ of Eq.(1) are all points that satisfy the equation:

$$
f\left(y^{*}\right)=0
$$

Depending on the complexity, Eq.(2) can be solved analytically or numerically. Determining equilibrium points without having to solve the differential equation is an important advantage of PPM.

4. Type of equilibrium point. Depending on the sign of the first derivative in equilibrium point, it may be stable (sink) or unstable (source):

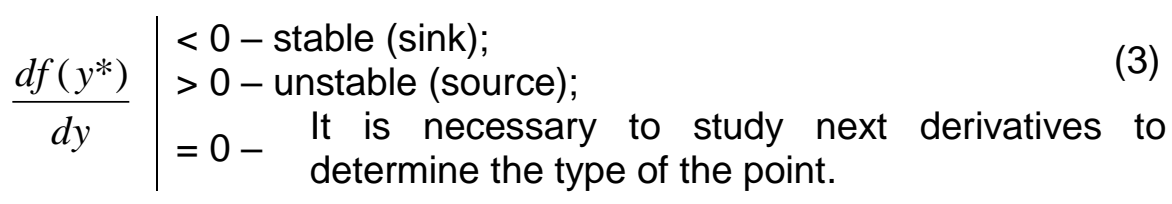

5. Direction of phase trajectory. It determines the type of equilibrium points - stable or unstable. For the directions of the trajectories, the rule is that in the first and the second quadrant the argument grows and in the third and fourth it decreases. If the direction of the trajectory in the vicinity of the fixed point is to the point, then it is a sink-type. If there is a difference from the point, there is a source type. The ability to determine the type of stability in two ways is one of the advantages of PPM, which makes it preferable in systems research.

6. Bifurcation point. It is defined for systems where the stability depends on parameter [2]. At the bifurcation point, minor changes in the value of the parameter lead to significant changes in stability. If a system works far from any point of bifurcation, it is likely that the disturbance will not lead to a qualitative change in its behaviour; and vice versa, the behaviour of a system operating close to a bifurcation point can change dramatically in the case of a noise impact.

\section{ANALYSIS OF ORDINARY DIFFERENTIAL EQUATIONS OF FIRST ORDER}

MathCad does not have Phase Trajectory procedures. However, the available toolbox allows creating an algorithm to allow ODE to be analyzed aplying the PPM method.

IRITIE Vol. 6, No. 2, 2018 ISSN 1314-8788 (print), ISSN 1314-8796 (online), doi: 10.15547/artte.2018.02.008 


\section{ARTTE $Y$}

Ipplied Resseirlohes in Technics, Technologies and Bductation

Journal of the Faculty of Technics and Technologies, Trakia University https://sites.google.com/a/trakia-uni.bg/artte/

The recommended algorithm is as follows.

1. Definition of phase plane. The abscissa is the dependent variable $\boldsymbol{y}$, and the differential is the ordinate, i.e. Cartesian coordinate system $\boldsymbol{d y} / \boldsymbol{d} \boldsymbol{x}$ vs $\boldsymbol{y}$ is created.

2. The phase trajectory $f(y)$ is built. In MathCad this can be done in two ways:

- Choice: Insert > Graph > X-Y Plot

- Command: “@”

The graph helps to visualize the behaviour of the function and approximately determine its roots, which are the desired equilibrium points.

3. Finding the equilibrium points of Eq.(2) and plot them in phase plane. The solution of the equation can be done symbolically and obtain the roots explicitly. In MathCad environment, the "solve" command can be used. The syntax is:

$$
q:=f(y) \text { solve, } y \rightarrow \quad / / \boldsymbol{q} \text { - vector with the roots of the function } \boldsymbol{f}(\boldsymbol{y})
$$

If $f(y)$ is a transcendent function or MathCad is unable to execute the "solve" command, it is possible to find the roots by a numerical method. Two programs being appropriate for this purpose. The "root" program finds one root in the interval $[\boldsymbol{a}, \boldsymbol{b}]$ :

$$
\mathrm{q}:=\operatorname{root}(\mathrm{f}(\mathrm{y}), \mathrm{y},[\mathrm{a}, \mathrm{b}]) / / \boldsymbol{q}-\text { root in the interval }[\mathbf{a}, \boldsymbol{b}]
$$

An estimate of the interval $[\boldsymbol{a}, \boldsymbol{b}]$ of a possible solution can be made on the graph of $f(y)$. An another program, which finds all roots but only on algebraic polynomial is "polyroots". For this operation, the coefficients of the polynomial $f(y)$ are required. They can be set explicitly by dialog or can be obtained with a command "coeffs":

$$
\begin{aligned}
& v:=f(y) \operatorname{coeffs} \rightarrow / / \boldsymbol{v} \text { - vector with coefficients of the polynomial } \mathbf{f}(\boldsymbol{y}) \\
& \mathbf{q}:=\text { polyroots }(\mathrm{v}), \quad / / \boldsymbol{q} \text { - vector with the roots of the polynomial } \mathbf{f}(\boldsymbol{y})
\end{aligned}
$$

Once fixed points are known, their type should be determined.

4. Finding the first derivative $\frac{d f(y)}{\mathrm{dy}}$ needed to determine the type of equilibrium points and the flow between them. Let the identifier of the first derivative be $\boldsymbol{d 1}(y)$. The command line for analytic differentiation is:

$$
d 1(y):=\frac{d}{d x} f(y) \rightarrow / / \text { symbolic form of the first derivative of } \boldsymbol{f}(\boldsymbol{y})
$$

The differentiation operator is available in the "Calculus Toolbar" or is called with the "?" key.

The joint drawing of $\boldsymbol{f}(\boldsymbol{y})$ and $\boldsymbol{d 1}(\boldsymbol{y})$ allows the point type to be determined in accordance with Eq.(3). An exact result is obtained by replacing the argument of the derivative with equilibrium points.

5. A flow between the fixed points of phase trajectory. MathCad does not allow to place arrows on graphs which define the flow direction. If necessary, it is advisable to mark the chart and then export with the clipboard $(\mathrm{Ctrl}+\mathrm{C})$ to a suitable graphics editor for final graph processing. As mentioned above, in the first and the second quadrant the argument grows, and in the third and fourth it decreases.

6. Bifurcation analysis. The function that describes a dynamic system may depend on a parameter. Bifurcation analysis gives an answer to the question of what parameter values the dynamic trajectory of the dynamic system changes qualitatively its behaviour.

IRTIIE Vol. 6, No. 2, 2018 ISSN 1314-8788 (print), ISSN 1314-8796 (online), doi: 10.15547/artte.2018.02.008 


\section{ART'TH $Y$}

Ipplied Resseirlohes in Technics, Technologies and Bductation

Journal of the Faculty of Technics and Technologies, Trakia University https://sites.google.com/a/trakia-uni.bg/artte/

The differential equation is stable at a given value of the parameter if the qualitative structure of the trajectory does not change with sufficiently small variations of the parameter. Such equation in the presence of bifurcation parameter $\boldsymbol{b}$ has the form:

$$
\frac{d y}{d x}=f(y, b)
$$

A small change of parameter $\boldsymbol{b}$ is expected to lead to major changes in the system's longterm behaviour. In order to investigate this influence, dependency is built:

$$
y=y(b)
$$

By this function, it is possible to determine how fixed $\boldsymbol{y}^{*}$ depends on parameter $\boldsymbol{b}$. Stability of $\boldsymbol{y}^{\boldsymbol{*}}$ in function of $\boldsymbol{b}$ will occur if:

$$
\frac{d f\left(y^{*}, b\right)}{d x}<0
$$

The importance of bifurcation analysis in systems design is clear. The determination of bifurcation points guarantees the correct choice of parameter $\boldsymbol{b}$ with the desired stability margins.

\section{EXAMPLE}

The subject of the study is the dose-response curve that determines the effective dose of the drug. The effective dose was determined experimentally, after which the resulting sigmoidal curve was identified with an appropriate function [1]. The identification of the dose-response curve with a first-order non-linear differential equation is examined in [6]. It is more complicated to determine the effective dose for multi-component drugs [7,8]. An optimization approaches for binary drugs are proposed in $[9,10]$. In the present example, a dose-response relationship model will be analyzed, in which an additional term $\boldsymbol{b} . \boldsymbol{y}(\boldsymbol{x})$, reflecting the influence of a second drug ingredient, is added. The effect is simplified and reduced to a proportional impact with parameter $\boldsymbol{b}$ of the instant dose of the main ingredient. Positive value of $\boldsymbol{b}$ represents an effect of synergy, and negative - antagonism. The equation in this case has the form:

$$
\begin{aligned}
& \mid \begin{array}{l}
\frac{d y(x)}{d x}=r\left[1-\frac{y(x)}{k}\right] \cdot y(x)+b \cdot y(x) \\
\mathrm{y}(0)=\mathrm{y}_{0}
\end{array} \\
& \text { where: } \mid x \text { - dose of a main drug } \\
& y(x): \mathfrak{R} \rightarrow[0,1] \text { - dose response curve; } \\
& r \text { - the rate constant of the process; } \\
& \mathrm{k} \text { - the asymptotic limit of growth; } \\
& \text { b - parameter, presenting the influence of the second drug. }
\end{aligned}
$$

The attention is to the dose-response curve of the antibiotic tubazid [6]. The experimental data and the identified curve are in Figure 1.

1. Phase plane definition. The phase-trajectory equation is used:

$$
f(y, b):=r\left(1-\frac{y}{k}\right) y+b \cdot y
$$

Cartesian coordinate system $\boldsymbol{f}(\boldsymbol{y}, \boldsymbol{b})$ vs $\boldsymbol{y}$ is created.

IRTIIE Vol. 6, No. 2, 2018 ISSN 1314-8788 (print), ISSN 1314-8796 (online), doi: 10.15547/artte.2018.02.008 


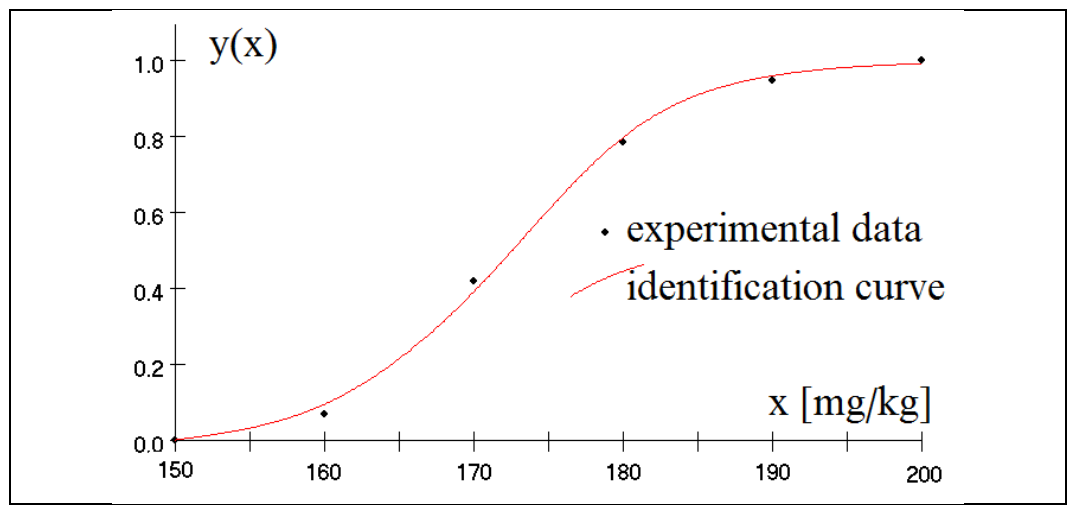

Figure 1. Identified dose-response relationship of tubazid. $y_{0}=0.15 ; r=0.182 ; k=1 ; b=0.15$

2. The graph is in Figure 2a. The visual analysis shows that there are two equilibrium points with values around 0 and 1 .

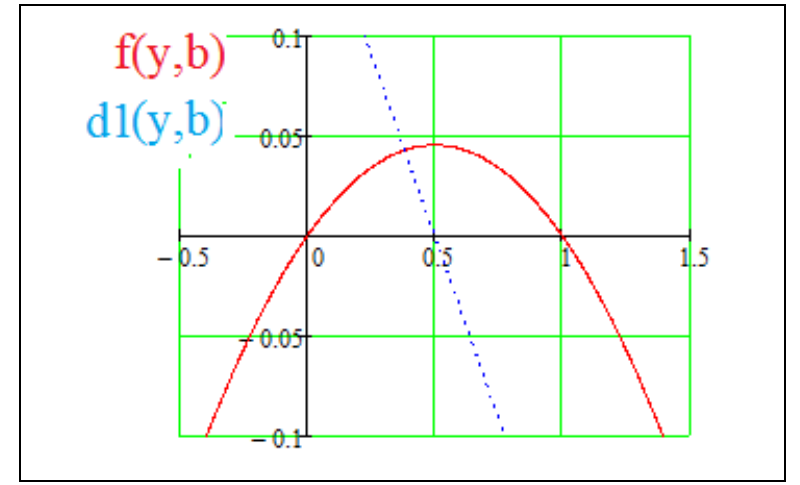

Figure 2a. Phase path and first derivative

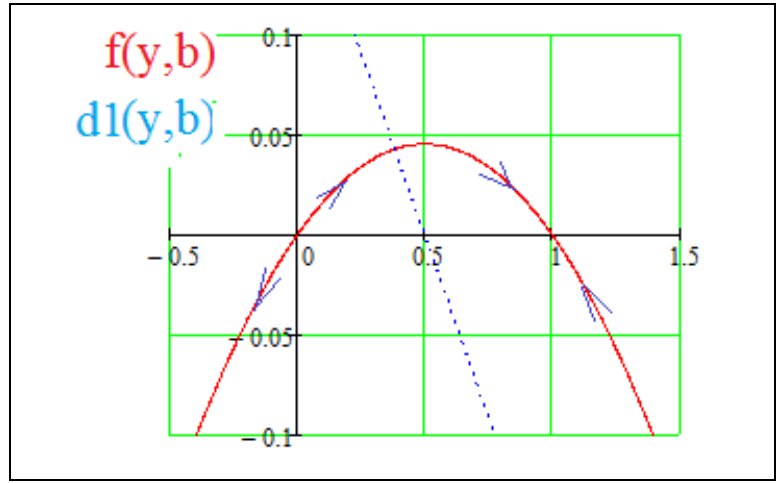

Figure $2 b$. Local flows around the fixed points

3. Equilibrium points. The exact values are found by solving equation (8). The solutions being recorded in a vector $\boldsymbol{q}$ :

$$
q:=r\left(1-\frac{y}{k}\right) \cdot y+b \cdot y \text { solve, } \mathrm{y} \rightarrow\left(\begin{array}{c}
0 \\
\mathrm{k} \cdot(\mathrm{b}+\mathrm{r}) \\
\mathrm{r}
\end{array}\right)
$$

Numerical values are:

$$
q=\left(\begin{array}{l}
0 \\
1
\end{array}\right)
$$

The type of stability of each of them is determined by the sign of the first derivative. It can be seen from Figure 2 that the derivative in the neighborhood of $q[0]$ has a positive value and that defines this fixed point as unstable, whereas for $q[1]$ the derivative is negative and the point is stable.

4. Analytic expression for the first derivative. This is the other, accurate way to determine the stability of the system. The next operator differentiates $f(y, b)$ and collect the terms of the expression containing like powers of a specified variable $\boldsymbol{y}$ :

$$
d 1(y):=\frac{d}{d y}\left[r\left(1-\frac{y}{k}\right) y+b \cdot y\right] \text { collect, } \mathrm{y} \rightarrow-\frac{2 . r}{k} \cdot y+b+r
$$

IRTIIE Vol. 6, No. 2, 2018 ISSN 1314-8788 (print), ISSN 1314-8796 (online), doi: 10.15547/artte.2018.02.008 


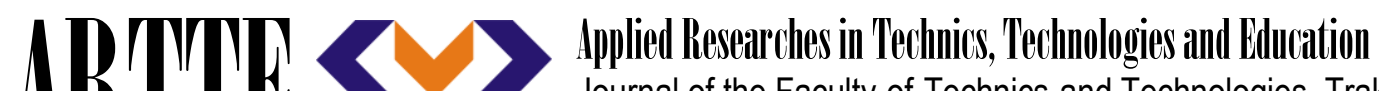 Journal of the Faculty of Technics and Technologies, Trakia University https://sites.google.com/a/trakia-uni.bg/artte/}

The values of the first derivative in fixed points are:

$$
d 1(q)=\left(\begin{array}{c}
0.332 \\
-0.032
\end{array}\right)
$$

Both the graph and numerical data show that the first fixed point is unstable, and the second one - stable.

5. Determination the flow between the fixed points. Once the fixed point type is established, this phase of the algorithm can be used to illustrate the result (Figure $2 b$ ).

6. Bifurcation analysis. Equation (8) is solved in relation to $\boldsymbol{y}$ in function of $\boldsymbol{b}$ :

$$
f(y, b):=\left(\frac{r}{k} \cdot y+b+r\right) \cdot y=0
$$

The graph is on Figure 3. Two bifurcation points are obtained:

$$
\left\{\begin{array}{l}
y_{1}(b)=0 \\
y_{2}(b)=\frac{k}{r} . b+k
\end{array}\right.
$$

$\boldsymbol{y}_{1}=\mathbf{0}$ is a fixed point for all values of $\boldsymbol{b}$.

The first derivative is:

$$
\frac{d}{d y} f(y, b)=-\frac{2 \cdot r}{k} \cdot y+r+b
$$

Its values at the bifurcation points are:

$$
\begin{aligned}
& \frac{d}{d y} f(0, b)=r+b<0 \Rightarrow b<-r \\
& \frac{d}{d y} f\left(\frac{k}{r} \cdot b+k, b\right)=-(r+b)<0 \Rightarrow b>-r
\end{aligned}
$$

The value of the bifurcation point is equal to the rate constant of the process $r=0.182$.

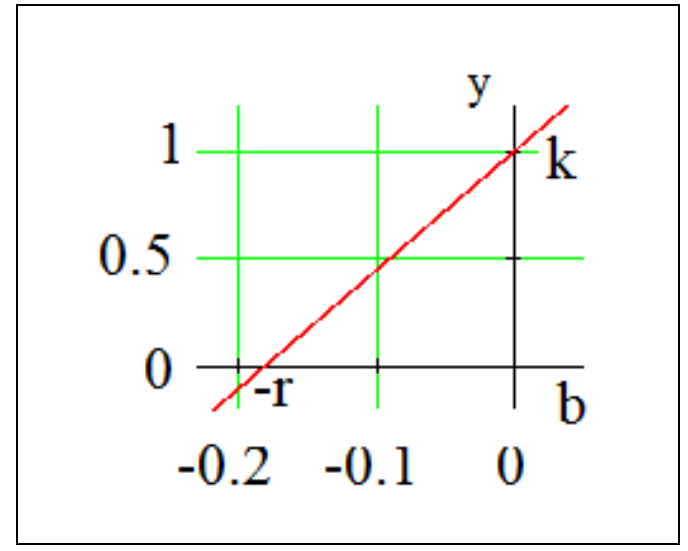

Figure 3. Bifurcation diagram

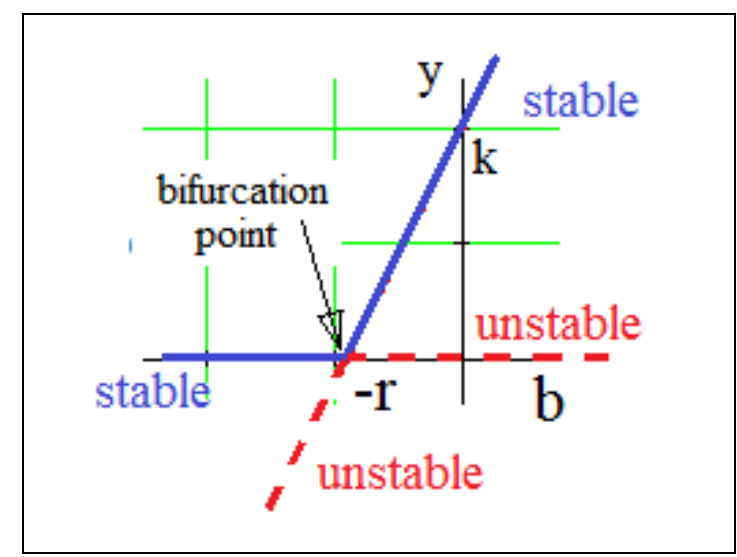

Figure 4. Transcritical bifurcation IRTIIE Vol. 6, No. 2, 2018 ISSN 1314-8788 (print), ISSN 1314-8796 (online), doi: 10.15547/artte.2018.02.008 


\section{ARTTLY $Y$}

Ipplied Resseirlohes in Technics, Technologies and Bductation

Journal of the Faculty of Technics and Technologies, Trakia University https://sites.google.com/a/trakia-uni.bg/artte/

At the bifurcation point $(\boldsymbol{b}, \boldsymbol{y})=(-r, 0)$ there is an exchange of stability. Before and after the bifurcation, there is one unstable and one stable fixed point (Fig.4). The stability is exchanged at the bifurcation point. Thus the unstable fixed point transforms into stable and vice versa. This type is called Transcritical bifurcation.

\section{CONCLUSION}

The Phase Plane method offers a non-trivial approach to determine the stability of dynamic systems without solving differential equations. In the paper the main concepts that characterize PPM are discussed. A sequence of operations in the MathCad environment for the investigation of systems and processes described by first-order differential equations is proposed. Both symbolic and numerical operators are proposed to solve tasks. As an example, the dose-dependent curve of the antibiotic tubazid is discussed. Two equilibrium points have been established. The first one is unstable and is at a zero dose, and the second one is stable to the saturation level, in this case, 1. A bifurcation analysis of the effect of the synergy parameter on the system stability has been made. Transcritical bifurcation was detected, and the point of bifurcation is determined by the rate constant of the process.

\section{ACKNOWLEDGMENTS}

This study was supported by Grant 2ФTT/31.03.2017, „Investigation of systems and processes by the phase plane method" from the Faculty of Technics and Technologies, Trakia University - Yambol, Bulgaria.

\section{REFERENCES}

[1] Bretz F., Hsu J., Pinheiro J., Liu Y. (2008). Dose Finding - A Challenge in Statistics. Biometrical Journal. Vol. 50 (4): 480-504.

[2] Hale J. K., Kocak H. (1991). Dynamics_and_Bifurcations. Springer Verlag New York, Inc.

[3] Jordan D. W., Smith P. (2007). Nonlinear ordinary differential equations. 4-th Ed. Oxford University Pres. ISBN 978-0-19-920824-1.

[4] Okereke, R.N. And Maliki, S.O. (2016) Asymptotic Behaviour of Solutions of Certain Third Order Nonlinear Differential Equations via Phase Portrait Analysis. Applied Mathematics, 7, 2324- 2335.

[5] Slotine J. E., Li W. (1991). Applied Nonlinear Control. Prentice Hall, Inc. Englewood Cliffs, New Jersey. ISBN 0-13-040890-5.

[6] Yankov K. (2010). Dose-Effect Modeling of Experimental Data. Journal of Information, Control and Management Systems, Vol. 8 (3), Slovakia, pp. 257-264. ISSN 1336-1716.

[7] Yankov K. (2014). Identification of Effective Doses in Binary Mixtures. Proc. Int. Conference on Information Technologies (InfoTech-2014). St. Constantine and Elena resort, Bulgaria, sept.18-20, 2014, pp. 316-324. ISSN 1314-1023.

[8] Yankov K. (2015). Selection of the Approximating Function for Isobologram Modeling. Proc. Int. Conference on Information Technologies (InfoTech-2015). St. Constantine and Elena resort, Varna, Bulgaria, sept.17-19, 2015. pp. 174-183. ISSN 1314-1023.

[9] Yankov K. (2016). Numerical Optimization of Binary Mixtures. Int. Journal of Pharma and Bio Sciences. 2016 July; 7 (3): 44-53. ISSN 0975-6299.

[10] Yankov K. (2016). Graphic Environment for Evaluation of Binary Mixtures. Int. Journal of Pharma and Bio Sciences. 2016 Oct; 7 (4): 308-316. ISSN 0975-6299. 